\title{
AOR
}

Selected Papers of \#AolR2021:

The 22nd Annual Conference of the

Association of Internet Researchers

Virtual Event / 13-16 Oct 2021

\section{CONSTRUCTING THE DIGITAL SKILLS CRISIS: A CRITICAL CONCEPTUAL HISTORY OF "SKILL"}

\author{
Lauren E. Bridges \\ University of Pennsylvania \\ Zane Griffin Talley Cooper \\ University of Pennsylvania \\ Julia Ticona \\ University of Pennsylvania
}

\section{Introduction}

For nearly two decades, scholars of digital inequalities have examined the ways that technological skills affect the benefits people derive from being online. From knowing how to apply for a job online, to participation in online knowledge production (Shaw \& Hargittai, 2018), scholars have demonstrated the key role skill plays in explaining current patterns in online activities today. Digital skills are often treated through the framework of human capital with the implicit assumption that new technologies create deficits in skills to be overcome by education, training, or "upskilling" (Davies \& Eynon, 2018). However, the cultural connections between skills and technology has both a history and a politics. In this paper, we explain the historical genealogy of technological skills, and its use as a political tool to order bodies according to the interests of power and capital.

\section{Literature Review}

Taking up Sara Ahmed's (2019) method of following words around, this paper follows skill-as a word, concept, and action-through its deep, yet critically sparse, intellectual history, to better understand how the idea of digital skills has been politically operationalized. This genealogy shows how, as a political concept, skill does not function as an intrinsic personal qualifier, but rather an extrinsic condition, an ordering logic imposed by power and capital. During the lateeighteenth and early-nineteenth centuries, the concept of skill was deployed largely as a political tool to organize changing relations of capital, and to maintain existing elite hierarchies (Wajcman, 1991; Kumar, 2018). The evolving coding of skilled vs. unskilled labor responded not just to the increased use of machines (Marx, 1990), but more acutely to the changing demographics of workers - to maintain patriarchal power as women entered the industrial workforce (Berg, 1994), to solidify hierarchies of colonial expertise (Kumar, 2018), and to fetishsize cultural techniques of Indigenous ways of knowing while exploiting Indigenous workers (Nakamura, 2014). In this way, skill began to take on a more instrumental meaning, as 
labor, both skilled and unskilled, became inextricably linked to doing work on/with machinery and, later, technology (Braudel, 1982).

Today, the concept skill exists in close rhetorical relation, and is often deployed alongside technology, innovation, and progress, as an individual pathway to economic mobility. Yet, "technology" is a comparatively recent concept, achieving its current dominant meanings only after World War II. Prior to the late-1940s, what we currently call technology was primarily referred to either as technics, mechanical arts, or industrial arts, which referred principally to specialized or artisanal knowledge and practice, not complex mechanical systems (Schatzberg, 2018). Conversely, the concept of technologie referred to an elite system of knowledge reserved for managers and royal officials who managed the artisanal trades (pp. 77-78). As such, technologie represented a hierarchical system of knowledge somewhat distinct from contemporary concepts like technics or mechanical arts.

\section{Executive construction of the "skills crisis"}

Using these entangled histories of skill and technology as a foundation, we trace this genealogy forward to see how skill is operationalized in executive level discourse. We analyze policies from four US presidents-from Clinton's digital divide policies, to Trump's executive order to "combat the skills crisis" - to understand the varying constructions of the technological skills crisis as a political project. Our findings show, although variations exist between democratic and republican framing - where one treats digital skills as democratizing and the other as a way to ensure national strength--there is a consistent deficit framework that individualizes a lack of appropriate skills which can only be addressed through training in new technologies. Who does this deficit-framed approach to digital skills serve? How might we reclaim an understanding of skills as a social collective that is essential to, and not separate from, technology? We argue that, by returning to and reexamining the conceptual roots of skill, we can better understand how skills discourses are related to technological progress, and how these discourses are deployed by powerful actors to achieve discrete political goals.

Presidential framing of policy issues has been shown to not only distinguish presidential speakers by style, but has material consequences on the way a president governs. Our findings show similarities across political ideologies that start from the same core assumption that skills are separate from and subordinate to technology. Instead, skills are defined externally by the interests of political and economic power and skills discourse is deployed to justify neoliberal and nationalist policy agendas. We assert, the pathologization of the "skills crisis" cannot be understood outside its political economic frame. Instead, we understand the skills crisis to be a political construction that organizes workers according to market-defined economic value.

Across political ideologies, skills are framed as a deficit issue that present both an opportunity for economic growth and a threat to national prosperity. However, the political framing splits based on the treatment of skills as an opportunity or threat. Where democratic administrations favored neoliberal policy solutions to meet market demands, republican administrations favored skills-based nationalism as a way to maintain global economic power. The Clinton administration positioned skills training as a way to bridge the "digital divide", which itself was understood as an issue of access to new technologies (Greene, 2016). Favoring the neoliberal consensus of the Left, Clinton's "Agenda for creating digital opportunity", was presented as an opportunity for disenfranchised workers to compete in the New Economy (The Clinton-Gore Agenda For Creating Digital Opportunity, 2000). The Bush administration, on the other hand, rolled out an "American Competitiveness Initiative", which aimed to make Amercia's "economic engine the envy of the world" and favored a skills-based nationalist frame.

\section{Conclusion}


Scholarship on digital inequalities has focused on the mechanism of digital skills to explain gaps in participation and outcomes from online activities. In this article, we critically analyze the concept of digital skills as a political project. First, through tracing genealogy of these terms, we illustrate that, although the idea of "technological skills" is a relatively recent invention, the concept of skill has been used to maintain classed, gendered, and racialized hierarchies among labor. Second, we find a consistent deficit framing of the crisis in digital skills through both republican and democratic executive discourse. This analysis contributes a historical and critical cultural perspective on a central analytical term for studies of digital inequalities, and suggests the necessity of critical interrogation of the idea of digital skills.

\section{References}

Ahmed, S. (2019). What's the use? On the uses of use. Duke University Press.

Braudel, F. (1992). Civilization and capitalism, 15th-18th century. University of California Press.

Davies, H. C., \& Eynon, R. (2018). Is digital upskilling the next generation our 'pipeline to prosperity'? New Media \& Society, 20(11), 3961-3979.

Greene, D. (2016). Discovering the Divide: Technology and Poverty in the New Economy. International Journal of Communication, 10(0), 20.

Kumar, A. (2018). Skilling and Its Histories: Labour Market, Technical Knowledge and the Making of Skilled Workers in Colonial India (1880-1910). Journal of South Asian Development, 13(3), 249-271. https://doi.org/10.1177/0973174118810050

Marx, L. (2010). Technology: The Emergence of a Hazardous Concept. Technology and Culture, 51(3), 561-577. https://doi.org/10.1353/tech.2010.0009

Nakamura, L. (2014). Indigenous Circuits: Navajo Women and the Racialization of Early Electronic Manufacture. American Quarterly, 66(4), 919-941.

Schatzberg, E. (2006). "Technik" Comes to America: Changing Meanings of "Technology" before 1930 on JSTOR. Technology and Culture, 47(3), 486-512.

Schatzberg, E. (2018). Technology: Critical history of a concept. The University of Chicago Press.

Shaw, A., \& Hargittai, E. (2018). The Pipeline of Online Participation Inequalities: The Case of Wikipedia Editing. Journal of Communication, 68(1), 143-168.

The Clinton-Gore Agenda For Creating Digital Opportunity. (2000).

Wajcman, J. (1991). Patriarchy, Technology, and Conceptions of Skill. Work and Occupations, 18(1), 29-45. https://doi.org/10.1177/0730888491018001002 